\title{
Affective temperaments of Lebanese patients with schizophrenia: comparison by gender and severity of psychosis
}

Joseph E. Dib ${ }^{1}$, Ilige Nehme ${ }^{2}$, Chadia Haddad ${ }^{3,4,6}$, Jocelyne Azar ${ }^{4,5}$, Souheil Hallit ${ }^{4,7^{*}+}$ (1) and Sahar Obeid ${ }^{6,8^{*}+}$

\begin{abstract}
Objectives: Our aim in this study was to identify affective temperament differences utilizing the TEMPS-A in a large sample size of Lebanese patients with schizophrenia and compare them to healthy controls. Gender differences, demographic factors and degree of psychotic symptoms were also considered. A cross-sectional study was conducted at the Psychiatric Hospital of the Cross (PHC) from March to June 2019. Two-hundred fifty chronic patients with schizophrenia were compared to 250 healthy controls randomly chosen from the general population.

Results: Patients with schizophrenia significantly had higher mean depressive, cyclothymic, irritable and anxious temperament scores compared to healthy controls. Healthy controls significantly had a higher mean hyperthymic temperament score compared to patients with schizophrenia. In the group of patients with schizophrenia exclusively, females scored higher in terms of depressive, cyclothymic and anxious temperaments compared to males. In the group of healthy controls, males scored higher in terms of hyperthymic and irritable temperaments compared to females, whereas a higher mean depressive and anxious temperament scores were significantly found in females compared to males. In addition, higher PANSS total scores, as well as higher positive, negative and general subscales scores were significantly associated with higher depressive, cyclothymic, irritable and anxious temperament scores.
\end{abstract}

Keywords: Schizophrenia, TEMPS-A, PANSS, Affective temperaments, Lebanese

\section{Introduction}

Individuals with schizophrenia present with varying symptoms and degrees of severity ranging from cognitive, emotional and psychological symptoms that affect their standing in the social and organizational domains [1]. The relationship temperament-psychiatric illness was first recognized by Emil Kraepelin who defined temperaments as personality characteristics whereby abnormal affective states may rise and ultimately lead to a full

\footnotetext{
*Correspondence: souheilhallit@hotmail.com; saharobeid23@hotmail.com †Souheil Hallit and Sahar Obeid are last co-authors.

${ }^{7}$ Faculty of Medicine and Medical Sciences, Holy Spirit University of Kaslik (USEK), Jounieh, Lebanon

${ }^{8}$ Faculty of Arts and Sciences, Holy Spirit University of Kaslik (USEK),

Jounieh, Lebanon

Full list of author information is available at the end of the article
}

blown affective illness [2]. Additionally, how personality changes in schizophrenia is still being debated with some citing the personality differences are on a continuum pre and post onset of schizophrenia while others have stated that the personality undergoes a dramatic change only post onset $[3,4]$. This, however, has led several researchers to develop temperamental dimensions: irritable, anxious, cyclothymic, depressive and hyperthymic $[5,6]$. Irritability is characterized by the tendency to be angry and reactive to slight provocations and disagreements [7]; anxious temperament is characterized by an excessive worry, often leading to impairments in social functioning and other aspects of an individual's life [8]; cyclothymic temperament is defined as a low grade mood instability often suffering from a recurrence of hypomanic and depressive mood swings [9] and finally, 
depressive temperament is characterized by low feelings of energy and mood while hyperthymic temperament is characterized by higher levels of energy and elevated mood levels [10].

The study of temperaments in different psychiatric samples have led to the development of the Temperamental Evaluation of Memphis, Pisa, Paris, and San DiegoAuto questionnaire (TEMPS-A) [11]. Temperament refers to innate behavioral style and how this behavior is expressed such as mood, persistence and adaptability; whereas personality is made up of characteristic patterns such as behavior, feelings and thoughts that develops throughout an individuals' life [12]. This cross-sectional study will focus solely on differences on affective temperaments as it is unable to show the changes of temperaments over time from the onset of schizophrenia. It can, however, highlight the degree of variation between two groups (schizophrenic patients and healthy control group) and might further highlight differences in gender and severity of psychotic symptoms. There have been studies linking temperaments and risk of having a psychotic episode [13-15] specifically how abnormal rates in temperament act as a precursor to a first time onset of schizophrenia [16], which have been conducted in Kenya [15], Finland [14] and Mexico [16].

Gender differences in individuals with schizophrenia are abundant in the psychiatric literature noting variation in symptomology, lifetime risk, course of onset and emotional variability [17]. However, little is known about temperamental differences in gender with patients with schizophrenia, with only one study assessing individuals with schizotypal personality disorder [18]. As for temperamental differences in healthy individuals, there are considerable differences between males and females [19]; while few studies have looked at temperamental differences between patients with schizophrenia and control groups, a multitude has not used the TEMPS-A questionnaire $[20,21]$ nor have assessed further differences in gender and its relation to severity of psychotic symptoms.

Furthermore, temperaments vary in different cultural settings whether in healthy individuals or within the psychiatric population [22]. As psychiatric research in the Middle East is generally low [23], the objective of this study was to identify affective temperaments in a large sample of Lebanese patients with schizophrenia, compare them to a healthy control group, and then do a comparison by gender, socio-economic factors and severity of psychosis. This study will seek to answer which temperaments would be more present in patients with schizophrenia compared to healthy controls, which temperaments would be more present in females compared to males and which temperaments would be associated with higher levels of psychosis. In this context, we hypothesize that (1) all temperaments would be higher among schizophrenic patients compared to healthy controls; (2) lower hyperthymic, higher depressive, anxious, irritable and cyclothymic temperaments would be associated with more psychosis; and (3) females would present higher levels of cyclothymic, depressive and anxious temperaments and lower irritable and hyperthymic temperaments than males.

\section{Main text \\ Methods \\ Study design and population}

A cross-sectional study was conducted at the Psychiatric Hospital of the Cross (PHC) from March to June 2019, enrolling 306 in-patients with schizophrenia. Patients were randomly chosen according to an online software (www.randomizer.org). Inclusion criteria included patients with schizophrenia (diagnosed by a physician according to the Diagnostic and Statistical Manual of Mental Disorders DSM-5) [24], a duration of hospitalization of more than a year and clinically stable -meaning patients are protected and prevented from harming themselves and/or others. Excluded were patients with schizo-affective disorder, those whose medications doses were variable and those who refused to participate in the study. Two-hundred fifty chronic patients with schizophrenia were compared to 250 healthy controls randomly chosen from the general population. For each patient, a healthy subject from the same gender, region and having the same age was chosen by words of mouth.

\section{Data collection and measures}

Patients and healthy individuals were interviewed by a clinical neuroscientist. The Arabic questionnaire took 20-30 min to complete. Medical files were assessed for the following information: (i) demographics (age, sex, geographic region, marital status, education level and total monthly salary per household), (ii) clinical information (family history of psychiatric disorders), (iii) social habits (smoking status, alcohol intake).

Affective temperament scale (TEMPS-A) Validated in Arabic [25], it contains 110 items for females and 109 for males [11] that assess depressive, cyclothymic, hyperthymic, irritable and anxious temperaments (yes/no type of answers). The Cronbach's alpha coefficients for the depressive temperament was (0.66), cyclothymic $(0.83)$, hyperthymic (0.82), irritable (0.76) and anxious $(0.88)$.

Positive and Negative Syndrome Scale (PANSS) PANSS, validated in Lebanon [26], measures symptom severity of schizophrenia. It evaluates positive, negative and general psychopathology symptoms rated on a 7-point 
Likert-scale $(1=$ absent, $7=$ extreme $)$ [27]. Cronbach's alphas were: positive symptoms (0.877), negative symptoms (0.933) and general psychopathology (0.926).

\section{Data analysis}

SPSS software v.25 was used for data analysis. Cronbach's alpha was recorded to ensure the reliability of the scales. The Student's independent t-test was used to compare continuous variables in two groups, whereas the ANOVA test was used when the comparison involved three or more groups. Pearson correlation was used to correlate two continuous variables. For categorical variables, the Chi-square and Fisher exact tests were used. $\mathrm{P}<0.05$ was considered significant.

\section{Results}

\section{Sample characteristics}

Table 1 shows the demographic characteristics of patients with schizophrenia and healthy controls stratified by gender. In the patients with schizophrenia group, males were significantly more likely to be single than females $(86.6 \%$ vs $69.8 \%$, p < 0.001$)$, unemployed (73.1\% vs $48.3 \%$, p < 0.001 ), with a low educational level (less than 8 years; $14.2 \%$ vs $3.4 \%, \mathrm{p}=0.006$ ) and with a family history of anxiety $(98.5 \%$ vs $82.8 \%$, p < 0.001$)$ compared to their female counterparts. In the group of patients with schizophrenia exclusively, a higher mean PANSS negative subscale score was significantly found in females compared to males (13.90 vs. 11.57, p $=0.031$ ).

\section{Affective temperaments differences}

Patients with schizophrenia significantly had higher mean depressive, cyclothymic, irritable and anxious temperament scores compared to healthy controls. Healthy controls significantly had a higher mean hyperthymic temperament score compared to patients with schizophrenia (Additional file 1: Table S1).

\section{Comparison differences by gender}

In the group of patients with schizophrenia exclusively, females scored higher in terms of depressive, cyclothymic and anxious temperaments compared to males. In the group of healthy controls, males scored higher in terms of hyperthymic and irritable temperaments compared to females, whereas a higher mean depressive and anxious temperament scores were significantly found in females compared to males (Additional file 1: Table S2).

In addition, higher PANSS total scores, as well as higher positive, negative and general subscales scores were significantly associated with higher depressive, cyclothymic, irritable and anxious temperament scores (Table 2).

\section{Discussion}

In this study, we aimed to compare affective temperament between patients with schizophrenia and a control group with no history of mental disorders as well as gender differences and degree of psychosis. To our knowledge, this was the first study of its kind in the Middle East.

Within affective temperament comparing both groups, depressive, cyclothymic, irritable and anxious temperaments were significantly higher in patients with schizophrenia when compared to healthy controls with the exception of hyperthymic being lower in the schizophrenia group when compared to the healthy group. As mentioned in the introduction, temperament is innate and the question if temperamental factors increase in the onset of schizophrenia is beyond the design scope of this study. Given the significant differences, it can be assumed a range of both biological and social factors contribute to these differences. As shown in Table 2, significant factors such as history of anxiety in the family as well as higher scores on the PANSS could highlight the differences in temperament.

Within the schizophrenia group, patients from both genders also scored higher in depressive and anxious temperament similar to other studies [28, 29]. Patients with schizophrenia suffer from stigma causing overwhelming stress that impacts them on the cognitive, emotional and social level which attribute to depressive and anxious symptoms [30]. Cyclothymic temperament was higher in individuals with schizophrenia. While the majority of work has compared cyclothymia to bipolar disorder, it has been noted that individuals with schizophrenia are at a higher risk of having cyclothymic symptoms which has also been linked as a predictive temperament of developing the disorder [31].

Assessing gender differences, females in the schizophrenia group scored higher on average when compared to their male counterparts on cyclothymic, depressive and anxious temperament which is congruent with the current literature [32]. Significantly higher depressive and anxious mean were found in females with schizophrenia compared to healthy females. In healthy subjects, men had a significantly higher mean in both hyperthymic and irritable temperaments compared to healthy women which could be attributed to the presence of higher levels of testosterone in males [33]. These gender differences of temperament can be due to hormonal differences between men and women [32]. 
Table 1 Sociodemographic and clinical characteristics of patients with schizophrenia and healthy control stratified by gender

\begin{tabular}{|c|c|c|c|c|c|c|}
\hline & \multicolumn{2}{|c|}{ Patients with schizophrenia $(n=250)$} & \multirow[t]{2}{*}{$p$ value } & \multicolumn{2}{|c|}{ Healthy controls $(n=250)$} & \multirow[t]{2}{*}{$p$ value } \\
\hline & Male & Female & & Male & Female & \\
\hline \multicolumn{7}{|l|}{ Education level } \\
\hline No education & $10(7.5 \%)$ & $19(16.4 \%)$ & 0.006 & $7(5.2 \%)$ & $8(6.9 \%)$ & 0.889 \\
\hline Less than 8 years & $60(44.8 \%)$ & $50(43.1 \%)$ & & $43(32.1 \%)$ & $35(30.2 \%)$ & \\
\hline 8 years & $45(33.6 \%)$ & $43(37.1 \%)$ & & $54(40.3 \%)$ & $44(37.9 \%)$ & \\
\hline College & $19(14.2 \%)$ & $4(3.4 \%)$ & & $30(22.4 \%)$ & $29(25.0 \%)$ & \\
\hline \multicolumn{7}{|l|}{ Work status } \\
\hline Unemployed & $98(73.1 \%)$ & $56(48.3 \%)$ & $<0.001$ & $35(26.1 \%)$ & $45(38.8 \%)$ & 0.032 \\
\hline Employed & $36(26.9 \%)$ & $60(51.7 \%)$ & & 99 (73.9\%) & $71(61.2 \%)$ & \\
\hline \multicolumn{7}{|l|}{ Monthly income } \\
\hline Less than $1000 \$$ & $25(67.6 \%)$ & $41(69.5 \%)$ & 0.447 & $25(25.3 \%)$ & $4(5.6 \%)$ & 0.003 \\
\hline $1000-2000 \$$ & $12(32.4 \%)$ & $18(30.5 \%)$ & & $62(62.6 \%)$ & $53(74.6 \%)$ & \\
\hline More then $2000 \$$ & - & - & & $12(12.1 \%)$ & $14(19.7 \%)$ & \\
\hline \multicolumn{7}{|l|}{ Marital status } \\
\hline Single & $116(86.6 \%)$ & $81(69.8 \%)$ & $<0.001$ & $44(32.8 \%)$ & $21(18.1 \%)$ & 0.002 \\
\hline Married & $7(5.2 \%)$ & $21(18.1 \%)$ & & $69(51.5 \%)$ & 77 (66.4\%) & \\
\hline Widowed & 0 & $7(6.0 \%)$ & & $10(7.5 \%)$ & $16(13.8 \%)$ & \\
\hline Divorced & $11(8.2 \%)$ & $7(6.0 \%)$ & & $11(8.2 \%)$ & $2(1.7 \%)$ & \\
\hline \multicolumn{7}{|l|}{ Family history of mental illness } \\
\hline Yes & $112(83.6 \%)$ & 95 (81.9\%) & 0.725 & & & \\
\hline No & $22(16.4 \%)$ & $21(18.1 \%)$ & & & & \\
\hline \multicolumn{7}{|l|}{ Family history of depression } \\
\hline Yes & $124(92.5 \%)$ & $101(87.1 \%)$ & 0.151 & & & \\
\hline No & $10(7.5 \%)$ & $15(12.9 \%)$ & & & & \\
\hline \multicolumn{7}{|l|}{ Family history of anxiety } \\
\hline Yes & $132(98.5 \%)$ & $96(82.8 \%)$ & $<0.001$ & & & \\
\hline No & $2(1.5 \%)$ & $20(17.2 \%)$ & & & & \\
\hline \multicolumn{7}{|l|}{ Family history of suicide } \\
\hline Yes & $126(94.0 \%)$ & $106(91.4 \%)$ & 0.419 & & & \\
\hline No & $8(6.0 \%)$ & $10(8.6 \%)$ & & & & \\
\hline \multicolumn{7}{|l|}{ Family history of drug abuse } \\
\hline Yes & $127(94.8 \%)$ & $108(93.1 \%)$ & 0.579 & & & \\
\hline \multirow[t]{2}{*}{ No } & $7(5.2 \%)$ & $8(6.9 \%)$ & & & & \\
\hline & Mean \pm SD & Mean \pm SD & $p$ value & Mean \pm SD & Mean \pm SD & $p$ value \\
\hline Age & $52.34 \pm 11.73$ & $50.49 \pm 11.19$ & 0.207 & $51.43 \pm 12.13$ & $51.35 \pm 10.86$ & 0.961 \\
\hline Duration of illness (in years) & $31.85 \pm 11.63$ & $30.68 \pm 10.75$ & 0.410 & & & \\
\hline Total PANSS score & $50.53 \pm 33.87$ & $58.67 \pm 38.40$ & 0.076 & & & \\
\hline Positive subscale & $12.13 \pm 8.86$ & $13.97 \pm 10.54$ & 0.140 & & & \\
\hline Negative subscale & $11.57 \pm 8.24$ & $13.90 \pm 8.61$ & 0.031 & & & \\
\hline General subscale & $26.82 \pm 18.86$ & $30.79 \pm 21.19$ & 0.119 & & & \\
\hline
\end{tabular}

Numbers in bold refer to significant $p$ values

PANSS Positive and Negative Syndrome Scale

Results showed that higher total PANSS scores, negative PANSS and general PANSS were significantly associated with higher mean of depressive, irritable and cyclothymic temperament, in concordance with other studies $[20,34]$. The presence of positive and negative symptoms severely impacts the dynamics of social interactions making it difficult to establish a positive relationship which can often be frustrating to both the individual with schizophrenia and healthy subjects [35]. 
Table 2 Association between PANSS scores and temperaments in patients with schizophrenia

\begin{tabular}{|c|c|c|c|c|c|c|c|c|c|c|}
\hline & \multicolumn{10}{|c|}{ Temperaments } \\
\hline & Depressive & $p$ value & Cyclothymic & $p$ value & Hyperthymic & $p$ value & Irritable & p value & Anxious & $p$ value \\
\hline & Mean \pm SD & & Mean \pm SD & & Mean \pm SD & & Mean \pm SD & & Mean \pm SD & \\
\hline \multicolumn{11}{|l|}{ PANSS ${ }^{a}$} \\
\hline Mild & $0.62 \pm 0.14$ & 0.005 & $0.47 \pm 0.17$ & $<0.001$ & $0.50 \pm 0.17$ & 0.988 & $0.37 \pm 0.21$ & 0.127 & $0.49 \pm 0.24$ & 0.015 \\
\hline Moderate & $0.65 \pm 0.16$ & & $0.53 \pm 0.13$ & & $0.50 \pm 0.15$ & & $0.41 \pm 0.18$ & & $0.59 \pm 0.17$ & \\
\hline Marked & $0.68 \pm 0.12$ & & $0.58 \pm 0.13$ & & $0.49 \pm 0.16$ & & $0.44 \pm 0.17$ & & $0.57 \pm 0.17$ & \\
\hline \multirow[t]{2}{*}{ Severe } & $0.70 \pm 0.14$ & & $0.58 \pm 0.13$ & & $0.49 \pm 0.19$ & & $0.44 \pm 0.18$ & & $0.59 \pm 0.18$ & \\
\hline & $\begin{array}{l}\text { Correlation } \\
\text { coefficient }\end{array}$ & $p$ value & $\begin{array}{l}\text { Correlation } \\
\text { coefficient }\end{array}$ & p value & $\begin{array}{l}\text { Correlation } \\
\text { coefficient }\end{array}$ & p value & $\begin{array}{l}\text { Correlation } \\
\text { coefficient }\end{array}$ & p value & $\begin{array}{l}\text { Correlation } \\
\text { coefficient }\end{array}$ & $p$ value \\
\hline Total PANSS score & 0.257 & $<0.001$ & 0.340 & $<0.001$ & -0.018 & 0.776 & 0.213 & 0.001 & 0.220 & $<0.001$ \\
\hline Positive subscale & 0.178 & 0.005 & 0.296 & $<0.001$ & -0.026 & 0.688 & 0.150 & 0.018 & 0.151 & 0.017 \\
\hline Negative subscale & 0.219 & $<0.001$ & 0.306 & $<0.001$ & -0.020 & 0.753 & 0.192 & 0.002 & 0.201 & 0.001 \\
\hline General subscale & 0.285 & $<0.001$ & 0.342 & $<0.001$ & -0.012 & 0.851 & 0.231 & $<0.001$ & 0.239 & $<0.001$ \\
\hline
\end{tabular}

Depressive temperament: mild vs. moderate ( 0.62 vs. $0.65, p=1.000)$; mild vs. marked ( 0.62 vs. $0.68, p=0.064)$; mild vs. severe $(0.62$ vs. $0.70, p=0.020)$; moderate vs. marked ( 0.65 vs. $0.68, p=1.000)$; moderate vs. severe $(0.65$ vs. $0.70, p=0.812)$; marked vs. severe $(0.68$ vs. $0.70, p=1.000)$

Cyclothymic temperament: mild vs. moderate $(0.47$ vs. $0.53, p=0.416)$; mild vs. marked $(0.47$ vs. $0.58, p=0.001)$; mild vs. severe $(0.47$ vs. $0.58, p=0.008)$; moderate vs. marked ( 0.53 vs. $0.58, p=1.000)$; moderate vs. severe $(0.53$ vs. $0.58, p=1.000)$; marked vs. severe $(0.58$ vs. $0.58, p=1.000)$

Hyperthymic temperament: mild vs. moderate $(0.50$ vs. $0.50, p=1.000)$; mild vs. marked $(0.50$ vs. $0.49, p=1.000)$; mild vs. severe $(0.50$ vs. $0.49, p=1.000)$; moderate vs. marked ( 0.50 vs. $0.49, p=1.000)$; moderate vs. severe ( 0.50 vs. $0.49, p=1.000)$; marked vs. severe $(0.49$ vs. $0.49, p=1.000)$

Irritable temperament: mild vs. moderate ( 0.37 vs. $0.41, p=1.000)$; mild vs. marked $(0.37$ vs. $0.44, p=0.376)$; mild vs. severe $(0.37$ vs. 0.44 , $p=0.497)$; moderate vs. marked ( 0.41 vs. $0.44, p=1.000)$; moderate vs. severe ( 0.41 vs. $0.44, p=1.000)$; marked vs. severe $(0.44$ vs. $0.44, p=1.000)$

Anxious temperament: mild vs. moderate ( 0.49 vs. $0.59, p=0.114)$; mild vs. marked ( 0.49 vs. $0.57, p=0.200)$; mild vs. severe $(0.49$ vs. 0.59 , $p=0.236)$; moderate vs. marked ( 0.59 vs. $0.57, p=1.000)$; moderate vs. severe ( 0.59 vs. $0.59, p=1.000)$; marked vs. severe $(0.57$ vs. $0.59, p=1.000)$

Numbers in bold refer to significant $p$ value

PANSS Positive and Negative Syndrome Scale

${ }^{\text {a }}$ Post hoc analysis for PANSS categories taking the temperaments as the dependent variables

Looking at sociodemographic outcomes, people diagnosed with schizophrenia fare poorly compared with those who do not meet the diagnosis, especially at being unemployed and being single [36]. Individuals in the schizophrenia group also had poorer levels of education, which ultimately affects their work status. This in turn affects their employment chances making it difficult to support themselves.

\section{Conclusion}

This is the first study of its kind using the TEMPS in patients with schizophrenia while assessing the comparison between gender and the severity of psychotic symptoms. Both males and females fared poorly in the schizophrenia group compared to healthy controls. The schizophrenia group tended to have higher levels of anxious, cyclothymic, depressive and irritable temperaments, and were more likely to be single and unemployed. Females in the schizophrenia group also tended to score higher in these temperaments compared to their male counterparts. Future studies should consider the possible role of cultural influence on the sampled population. As depressive, cyclothymic and anxious temperaments are significantly present with higher PANSS scores, clinicians and caretakers should take into consideration this dynamic is not a cause and effect but rather a cycle.

\section{Limitations}

While not many studied worked on this topic, final results should be considered preliminary and not enough to generalize. Differences in scores between genders in both the schizophrenia group and healthy controls require a larger sample size. In addition, this was a cross a cross-sectional study and therefore we cannot give evidence of causality. Furthermore, we should be aware of the issue of validity of personality questionnaires, which is not well established in psychotic patients. Finally, results of this study cannot differentiate between depressive temperament and negative symptoms associated with schizophrenia. Future longitudinal studies are recommended in order to study the causality between the latter variables.

\section{Abbreviations}

PHC: Psychiatric Hospital of the Cross; TEMPS-A: Affective temperament scale; PANSS: Positive and Negative Syndrome Scale. 


\section{Supplementary Information}

The online version contains supplementary material available at https://doi. org/10.1186/s13104-021-05854-8.

Additional file 1: Figure S1. Flow diagram. Table S1. Comparison of temperaments between patients with schizophrenia and healthy controls. Table S2. Comparison of temperaments between patients with schizophrenia and healthy controls by gender.

\section{Acknowledgements}

The authors would like to thank the patients and the participants who helped them in this study and Miss Ghina El-Seddik for her help in the data collection. This work has been done in the frame of the "Behavioral and Cognitive Neuroscience Master 2 program", Faculty of Sciences, Lebanese University.

\section{Authors' contributions}

$\mathrm{SO}$ and $\mathrm{SH}$ conceived and designed the survey. $\mathrm{CH}$ and $\mathrm{SH}$ were involved in the statistical analysis and data interpretation. JED and IN wrote the manuscript. JA reviewed the manuscript. IN involved in the data collection and data entry. All authors read and approved the final manuscript.

\section{Funding}

None.

\section{Availability of data and materials}

All data generated or analyzed during this study are not publicly available to maintain the privacy of the individuals' identities. The dataset supporting the conclusions is available upon request to the corresponding author.

\section{Declarations}

\section{Ethics approval and consent to participate}

The Psychiatric Hospital of the Cross Ethics and Research Committee approved this study protocol in compliance with the Hospital's Regulatory Research Protocol (HPC-010-2019). A written informed consent was obtained from each participant.

\section{Consent for publication \\ Not applicable.}

\section{Competing interests}

The authors have nothing to disclose.

\section{Author details}

${ }^{1}$ Division of Psychiatry and Clinical Psychology, School of Medicine, University of Nottingham, Nottingham, UK. ${ }^{2}$ Faculty of Science, Lebanese University, Fanar, Lebanon. ${ }^{3}$ Institute of Epidemiology and Tropical Neurology, INSERM, University of Limoges, CH Esquirol, UMR 1094, Tropical Neuroepidemiology, GEIST, 87000 Limoges, France. ${ }^{4}$ Research Department, Psychiatric Hospital of the Cross, Jal Eddib, Lebanon. ${ }^{5}$ Faculty of Medicine, Lebanese American University, Byblos, Lebanon. ${ }^{6}$ INSPECT-LB: Institut National de Santé Publique, Epidemiologie Clinique Et Toxicologie, Beirut, Lebanon. ${ }^{7}$ Faculty of Medicine and Medical Sciences, Holy Spirit University of Kaslik (USEK), Jounieh, Lebanon. ${ }^{8}$ Faculty of Arts and Sciences, Holy Spirit University of Kaslik (USEK), Jounieh, Lebanon.

Received: 21 February 2021 Accepted: 16 November 2021 Published online: 25 November 2021

\section{References}

1. Kaplan HI, Sadock BJ. Synopsis of psychiatry: behavioral sciences clinical psychiatry. 5th ed. Baltimore: Williams \& Wilkins Co.; 1988.

2. Kraepelin E. Manic depressive insanity and paranoia. J Nerv Ment Dis. 1921;53(4):350

3. Smith TE, Shea MT, Schooler NR, Levin H, Deutsch A, Grabstein E. Personality traits in schizophrenia. Psychiatry. 1995;58(2):99-112.
4. Hulbert CA, Jackson HJ, McGorry PD. Relationship between personality and course and outcome in early psychosis: a review of the literature. Clin Psychol Rev. 1996;16(8):707-27.

5. Akiskal HS. Toward a definition of generalized anxiety disorder as an anxious temperament type. Acta Psychiatr Scand Suppl. 1998;393:66-73.

6. Placidi GF, Signoretta S, Liguori A, Gervasi R, Maremmani I, Akiskal HS. The semi-structured affective temperament interview (TEMPS-I). Reliability and psychometric properties in 1010 14-26-year old students. J Affect Disord. 1998:47(1-3):1-10.

7. Caprara GV, Cinanni V, D'imperio G, Passerini S, Renzi P, Travaglia G. Indicators of impulsive aggression: present status of research on irritability and emotional susceptibility scales. Personal Individual Differ. 1985:6(6):665-74.

8. Akiskal HS. Toward a definition of generalized anxiety disorder as an anxious temperament type. Acta Psychiatr Scand. 1998;98(s393):66-73.

9. Perugia G, Hantouchec E, Vannucchia G. Diagnosis and treatment of cyclothymia: the "primacy" of temperament. Curr Neuropharmacol. 2017;15(3):372-9.

10. Boldrini T, Mancinelli E, Erbuto D, Lingiardi V, Muzi L, Pompili M, Ducci G, Salcuni S, Tanzilli A, Venturini P. Affective temperaments and depressive symptoms: the mediating role of attachment. J Affect Disord. 2021:293:476-83.

11. Akiskal HS, Akiskal KK. TEMPS: temperament evaluation of Memphis, Pisa, Paris and San Diego. J Affect Disord. 2005:85(1-2):1-2.

12. Caspi A, Shiner R. Temperament and personality. Blackwell: Wiley; 2008.

13. Song YY, Kang Jl, Kim SJ, Lee MK, Lee E, An SK. Temperament and character in individuals at ultra-high risk for psychosis and with firstepisode schizophrenia: associations with psychopathology, psychosocial functioning, and aspects of psychological health. Compr Psychiatry. 2013;54(8):1161-8.

14. Poustka L, Murray G, Jääskeläinen E, Veijola J, Jones P, Isohanni M, Miettunen J. The influence of temperament on symptoms and functional outcome in people with psychosis in the Northern Finland 1966 Birth Cohort. Eur Psychiatry. 2010;25(1):26-32.

15. Mamah D, Cloninger CR, Mutiso VN, Gitonga I, Tele A, Ndetei DM. Personality traits as markers of psychosis risk in Kenya: assessment of temperament and character. Schizophr Bull Open. 2020;1 (1):sgaa051.

16. Fresán A, León-Ortiz P, Robles-García R, Azcárraga M, Guizar D, ReyesMadrigal F, Tovilla-Zárate CA, de la Fuente-Sandoval C. Personality features in ultra-high risk for psychosis: a comparative study with schizophrenia and control subjects using the temperament and character inventory-revised (TCI-R). J Psychiatr Res. 2015;61:168-73.

17. Häfner H. Gender differences in schizophrenia. Psychoneuroendocrinology. 2003;28:17-54

18. Preti A, Corrias I, Gabbrielli M, Lai V, Muratore T, Pintus E, Pintus M, Sanna $S$, Scanu R, Tronci D, et al. The independence of schizotypy from affective temperaments - a combined confirmatory factor analysis of SPQ and the short TEMPS-A. Psychiatry Res. 2015;225(1-2):145-56.

19. Else-Quest NM, Hyde JS, Goldsmith HH, Van Hulle CA. Gender differences in temperament: a meta-analysis. Psychol Bull. 2006;132(1):33.

20. Hori H, Noguchi H, Hashimoto R, Nakabayashi T, Saitoh O, Murray RM, Okabe S, Kunugi H. Personality in schizophrenia assessed with the temperament and character inventory (TCl). Psychiatry Res. 2008;160(2):175-83.

21. Guillem F, Bicu M, Semkovska M, Debruille JB. The dimensional symptom structure of schizophrenia and its association with temperament and character. Schizophr Res. 2002;56(1-2):137-47.

22. Chess S, Thomas A. Temperament: theory and practice. Milton Park: Routledge; 2013.

23. Patel V, Sumathipala A. International representation in psychiatric literature: survey of six leading journals. Br J Psychiatry. 2001;178(5):406-9.

24. Association AP. Diagnostic and statistical manual of mental disorders (DSM-5 ${ }^{\circledR}$ ). Washington: American Psychiatric Pub; 2013.

25. Karam EG, Mneimneh Z, Salamoun M, Akiskal KK, Akiskal HS. Psychometric properties of the Lebanese-Arabic TEMPS-A: a national epidemiologic study. J Affect Disord. 2005;87(2-3):169-83.

26. Hallit S, Obeid S, Haddad C, Kazour F, Kazour G. Validation of the Arabic Version of the PANSS scale among Lebanese schizophrenic patients. J Psychopathol. 2017. https://doi.org/10.1016/j.encep.2018.05.004.

27. Kay S. Positive and negative symptom (PANNS) scale manual. Schizophr Bull. 1986;13:261-78. 
28. Margetić BA, Jakovljević M, Ivanec D, Margetić B, Tošić G. Relations of internalized stigma with temperament and character in patients with schizophrenia. Compr Psychiatry. 2010;51(6):603-6.

29. Vrbova K, Prasko J, Holubova M, Slepecky M, Ociskova M. Positive and negative symptoms in schizophrenia and their relation to depression, anxiety, hope, self-stigma and personality traits - a cross-sectional study. Neuroendocrinol Lett. 2018;39(1):9-18.

30. Rusch N, Corrigan PW, Wassel A, Michaels P, Olschewski M, Wilkniss S, Batia K. A stress-coping model of mental illness stigma: I. Predictors of cognitive stress appraisal. Schizophr Res. 2009;110(1-3):59-64.

31. van Valkenburg C, Kluznik JC, Speed N, Akiskal HS. Cyclothymia and labile personality: is all folie circulaire? J Affect Disord. 2006;96(3):177-81.

32. Akiskal KK, Akiskal HS. The theoretical underpinnings of affective temperaments: implications for evolutionary foundations of bipolar disorder and human nature. J Affect Disord. 2005;85(1-2):231-9.

33. Gonda X, Rihmer Z, ZsombokT, Bagdy G, Akiskal KK, Akiskal HS. The 5HTTLPR polymorphism of the serotonin transporter gene is associated with affective temperaments as measured by TEMPS-A. J Affect Disord. 2006;91(2-3):125-31.

34. Yazici E, Cimen Z, Akyollu IIU, Yazici AB, Turkmen BA, Erol A. Depressive temperament in relatives of patients with schizophrenia is associated with suicidality in patients with schizophrenia. Clin Psychopharmacol Neurosci. 2018;16(3):302.

35. Fett A-KJ, Shergill SS, Joyce DW, Riedl A, Strobel M, Gromann PM, Krabbendam $\mathrm{L}$. To trust or not to trust: the dynamics of social interaction in psychosis. Brain. 2012;135(3):976-84.

36. Hayes RL, Halford WK. Time use of unemployed and employed single male schizophrenia subjects. Schizophr Bull. 1996;22(4):659-69.

\section{Publisher's Note}

Springer Nature remains neutral with regard to jurisdictional claims in published maps and institutional affiliations.
Ready to submit your research? Choose BMC and benefit from:

- fast, convenient online submission

- thorough peer review by experienced researchers in your field

- rapid publication on acceptance

- support for research data, including large and complex data types

- gold Open Access which fosters wider collaboration and increased citations

- maximum visibility for your research: over 100M website views per year

At BMC, research is always in progress.

Learn more biomedcentral.com/submissions 